\title{
Dynamics of heart rate variability analysed through nonlinear and linear dynamics is already impaired in young type 1 diabetic subjects
}

\author{
Naiara M. Souza, ${ }^{1}$ Thais R. Giacon, ${ }^{1}$ Francis L. Pacagnelli, ${ }^{2}$ Marianne P. C. R. Barbosa, ${ }^{1}$ Vitor E. Valenti, ${ }^{3}$ \\ Luiz C. M. Vanderlei ${ }^{1}$ \\ ${ }^{1}$ Faculdade de Ciencias e Tecnologia - FCT/UNESP; ${ }^{2}$ Universidade do Oeste Paulista - UNOESTE, Presidente \\ Prudente; ${ }^{3}$ Faculdade de Filosofia e Ciências - FFC/UNESP, Marília, SP, Brazil
}

\begin{abstract}
Background: Autonomic diabetic neuropathy is one of the most common complications of type 1 diabetes mellitus, and studies using heart rate variability to investigate these individuals have shown inconclusive results regarding autonomic nervous system activation. Aims: To investigate the dynamics of heart rate in young subjects with type 1 diabetes mellitus through nonlinear and linear methods of heart rate variability. Methods: We evaluated 20 subjects with type 1 diabetes mellitus and 23 healthy control subjects. We obtained the following nonlinear indices from the recurrence plot: recurrence rate (REC), determinism (DET), and Shanon entropy (ES), and we analysed indices in the frequency (LF and HF in ms2 and normalised units - nu - and LF/HF ratio) and time domains (SDNN and RMSSD), through analysis of $1000 \mathrm{R}-\mathrm{R}$ intervals, captured by a heart rate monitor. Results: There were reduced values $(\mathrm{p}<0.05)$ for individuals with type 1 diabetes mellitus compared with healthy subjects in the following indices: DET, REC, ES, RMSSD, SDNN, LF (ms2), and HF (ms2). In relation to the recurrence plot, subjects with type 1 diabetes mellitus demonstrated lower recurrence and greater variation in their plot, intergroup and intra-group, respectively. Conclusion: Young subjects with type 1 diabetes mellitus have autonomic nervous system behaviour that tends to randomness compared with healthy young subjects. Moreover, this behaviour is related to reduced sympathetic and parasympathetic activity of the autonomic nervous system.
\end{abstract}

Keywords: Diabetes mellitus type 1; autonomic nervous system; nonlinear dynamics; heart rate and young adult.

Received: 29 July 2015; Accepted: 2 December 2015; First published online: 3 February 2016

$\mathrm{D}$ IABETES MELLITUS AFFECTS 387 MILLION PEOPLE around the world; in Brazil, 9 million people above 18 years of age have this disease, and $10 \%$ of them have type 1 diabetes mellitus. Autonomic diabetic neuropathy is one of the most common complications of type 1 diabetes and generally impairs the cardiovascular system, resulting in autonomic neuropathy, ${ }^{1}$ significantly influencing the mortality rate of diabetic patients. ${ }^{2-4}$

In this context, we highlight the importance of studies that assess the dynamics of the autonomic

Correspondence to: N. M. Souza, Roberto Simonsen Street, 305 - Presidente Prudente, SP 19060-900, Brazil. Tel: + 5518 3229-5819; Fax: + $55183221-4391$; E-mail: naiara_bs@live.com nervous system, providing new elements on how neuropathies are developed and how they can change the sympathetic and parasympathetic systems. ${ }^{3}$

A method that is widely used to assess cardiac autonomic modulation is the analysis of heart rate variability. ${ }^{5}$ Heart rate variability describes the oscillations of the intervals between consecutive heart beats ( $\mathrm{R}-\mathrm{R}$ intervals) ${ }^{6-8}$ and it provides information on the diagnosis and prognosis of several diseases. ${ }^{9}$ Analysis of heart rate variability can be performed by linear methods, which include the indices in the time and frequency domains, and by nonlinear methods based on chaos theory.

Studies using heart rate variability that investigated type 1 diabetes mellitus by linear methods 
showed that this population may exhibit reduced modulation of the autonomic nervous system on both systems ${ }^{2,10,11}$ or only one system. ${ }^{12,13}$ Studies using nonlinear methods to investigate type 1 diabetes mellitus are scarce and have provided inconclusive results, indicating loss of complexity of the autonomic nervous system only in some indices. ${ }^{13-16}$

It is known that the nonlinear behaviour is prevalent in the human systems, and the study of heart rate variability by nonlinear methods has gained increasing interest, as the recurrence plot. ${ }^{17}$

The recurrence plot is a graphical representation of recurrence in a dynamic system and it evaluates the complexity of a system. ${ }^{18,19}$ The plot allows a qualitative analysis through vertical, horizontal, and diagonal variables and it also allows a quantitative analysis by means of its indices, ${ }^{18}$ thus enabling a more sensitive analysis of cardiac autonomic regulation.

In this sense, studying the nonlinear behaviour, which is more representative of the physiological behaviour of individuals, can lead to a better understanding of the influence of the autonomic nervous system on type 1 diabetes mellitus subjects and assist in the assessment and risk stratification of these patients. Therefore, better and specific treatment plans can be designed depending on autonomic nervous system action.

Thus, we aimed to evaluate the cardiac autonomic modulation of type 1 diabetes mellitus subjects at rest through qualitative and quantitative analyses of the recurrence plot.

\section{Materials and methods}

\section{Study population}

We analysed data from 43 young adult volunteers of both sexes who were divided into two groups: control and type 1 diabetes mellitus groups. We chose type I diabetes patients for this study because of the lower prevalence of co-morbidities associated with type 1 diabetes mellitus compared with type 2 diabetes mellitus, because co-morbidities of type 2 diabetes mellitus could influence autonomic nervous system modulation.

The type 1 diabetes mellitus group was composed of 20 volunteers diagnosed with type 1 diabetes mellitus, the time of diseases was $9.8 \pm 4.97$ years, and the control group consisted of 23 healthy volunteers. Table 1 contains the characterisation of the groups studied.

The inclusion criteria for selection were as follows: individuals who did not use drugs that influence cardiac autonomic regulation - such as $\beta$-blockers and adrenergic agonists - those who did not have cardio-respiratory diseases, and those who were non-smokers and did not consume alcohol. We excluded from the study volunteers who did not comply with the recommendations for performing the experimental procedure and those who had a series with more than $95 \%$ sinus rhythm.

All the study procedures were approved by the Ethics Committee in Research of our Institution (47/2011), and we followed the rules established by the 466/2012 Resolution of The National Health Council. The volunteers were fully informed about the procedures and objectives of this study, and all of them signed a consent form.

\section{Procedures}

Data were collected in our sound-proof laboratory. The temperature $\left(23.87 \pm 2.54^{\circ} \mathrm{C}\right)$ and humidity $(54.22 \pm 8.51 \%)$ were recorded by a digital thermo-hygrometer (Incoterm, Rio Grande do Sul, Brazil).

Initially, volunteers answered a questionnaire to identify and obtain information on age, signs and symptoms of type 1 diabetes mellitus, drug use, presence of associated diseases, evaluation of physical activity time performed in a week, measured through the IPAQ, ${ }^{20}$ and the age of disease onset among the volunteers. We performed physical assessments - anthropometric

Table 1. Mean values, followed by their respective standard deviations of physical and clinical characteristics of the studied volunteer groups.

\begin{tabular}{lccc}
\hline & DM1 $(\mathbf{n}=20)$ & Control $(\mathbf{n}=23)$ & p value \\
\hline Age (years) & $22.50 \pm 4.09[18-30]$ & $22.21 \pm 2.69[18-30]$ & 0.7882 \\
Height $(\mathrm{m})$ & $1.69 \pm 0.10[1.54-1.93]$ & $1.70 \pm 0.11[1.51-1.93]$ & 0.8636 \\
Weight $(\mathrm{kg})$ & $74.57 \pm 13.53[59.40-110.20]$ & $68.34 \pm 16.06[44.40-100.00]$ & 0.1927 \\
BMI $\left(\mathrm{kg} / \mathrm{m}^{2}\right)$ & $26.06 \pm 5.32[18.90-42.50]$ & $23.33 \pm 3.86[17.80-31.90]$ & 0.0560 \\
WHR & $0.78 \pm 0.05[0.67-0.87]$ & $0.79 \pm 0.07[0.65-0.93]$ & 0.4586 \\
HR (bpm) & $81.20 \pm 9.47[67-97]$ & $75.30 \pm 10.96[60-76]$ & 0.0684 \\
SBP $(\mathrm{mmHg})$ & $108.50 \pm 10.40[90.00-130.00]$ & $111.91 \pm 12.74[90.00-140.00]$ & 0.3462 \\
DBP (mmHg) & $68.00 \pm 8.94[50.00-80.00]$ & $73.04 \pm 9.26[60.00-100.00]$ & 0.0777 \\
PA weekly (minutes) & $566.35 \pm 686.31[0.00-3080.00]$ & $623.91 \pm 552.01[65.00-2040.00]$ & 0.4078 \\
\hline
\end{tabular}

$\mathrm{BMI}=$ body mass index; $\mathrm{bpm}=$ beats per minute; $\mathrm{DBP}=$ diastolic blood pressure; $\mathrm{DM} 1$ = diabetes mellitus type $1 ; \mathrm{HR}=$ heart rate; $\mathrm{kg}=\mathrm{kilograms}$; $\mathrm{m}=$ metres; $\mathrm{min}=$ minute; $\mathrm{mmHg}=$ millimetres of mercury; $\mathrm{PA}=$ physical activity; $\mathrm{SBP}=$ systolic blood pressure; WHR = waist/hip circumference Mean \pm standard deviation [minimum-maximum] 
measurement, heart rate and blood pressure at rest - and subsequently cardiac autonomic regulation was evaluated. All the procedures were conducted by a group of trained researchers.

\section{Physical assessment}

We measured the weight and height of the participants to calculate body mass index, and we measured waist circumference and hip circumference to obtain the waist/hip ratio.

Body mass was measured using a digital scale (Welmy R/I 200, Brazil) and height was measured using a stadiometer (Sanny, São Paulo, Brazil). Using the weight and height scores, body mass index was calculated using the formula weight $(\mathrm{kg}) /$ height (metres) squared. $^{21}$

To obtain the waist/hip ratio, we used a measuring tape (Sanny) for the measurement of waist circumference - which was obtained by measuring the smallest circumference between the lower costal margin and the anterior superior iliac crest - and hip circumference was obtained by measuring the diameter at the trochanters. To obtain the waist/hip ratio, the value of waist circumference was divided by the value of hip circumference. ${ }^{22}$

Blood pressure was measured indirectly, using the stethoscope (Littman, Saint Paul, Minnesota, United States of America) and aneroid sphygmomanometer (WelchAllyn - Tycos, New York, New York, United States of America), on the left arm of the volunteer following the criteria established by the VI Brazilian Guidelines on Hypertension blood. ${ }^{23}$

Heart rate was measured by palpation of the brachial artery for one minute.

\section{Autonomic assessment}

Volunteers were instructed to avoid consuming alcohol, caffeine and/or autonomic nervous system stimulants such as coffee, tea, and chocolate ${ }^{8}$ for 24 hours before evaluation. Data were collected between 1 p.m. and 6 p.m. All the procedures necessary for data collection were explained to the individuals, and the subjects were instructed to remain at rest and not to talk during the data collection process.

After all the procedures of data collection were explained to the volunteers, a strap that captures the heart electrical activity was placed on the sternum and the Polar S810i monitor was placed on the wrist (Polar Electro, Kempele, Finland). ${ }^{6,24}$ The participants were then placed supine on a stretcher where they remained at rest for 30 minutes with spontaneous breathing.

The $\mathrm{R}-\mathrm{R}$ intervals recorded by the portable validated heart rate monitor Polar S810i, ${ }^{4,5}$ - with a sampling rate of $1000 \mathrm{~Hz}$ - were uploaded to the Polar Precision Performance programme (v. 3.0; Polar Electro).
The software enabled the visualisation of heart rate and the extraction of a cardiac period ( $\mathrm{R}-\mathrm{R}$ interval) file in downloadable ".txt" format. Following digital filtering complemented with manual filtering for the elimination of premature ectopic beats and artefacts, ${ }^{25} 1000$ $\mathrm{R}-\mathrm{R}$ intervals were used for the data analysis. Only series with more than $95 \%$ sinus rhythm was included in the study.

For calculation of the indices, we used heart rate variability Analysis software (Kubios HRV v.1.1 for Windows; Biomedical Signal Analysis Group, Department of Applied Physics, University of Kuopio, Kuopio, Finland), whereas the nonlinear indices derived from the recurrence plot were obtained by Visual Recurrence Analysis - VRA (Visual Recurrence Analysis Software, by Eugene Kononov, United States of America) software.

\section{Analysis of heart rate variability indices}

All the following analyses of heart rate variability were conducted by a single researcher, and therefore all of quantitative and qualitative indices.

\section{Linear methods}

To analyse heart rate variability in the frequency domain, the low frequency $(\mathrm{LF}=0.04-0.15 \mathrm{~Hz}$, sympathetic component) and high frequency $(\mathrm{HF}=$ $0.15-0.40 \mathrm{~Hz}$, parasympathetic component) spectral components were used in absolute $\left(\mathrm{ms}^{2}\right)$ and normalised units (nu), which represent a value relative to each spectral component in relation to the total power minus the very low frequency components, and the ratio between these components $(\mathrm{LF} / \mathrm{HF})$. The spectral analysis was calculated using the Fast Fourier Transform algorithm. ${ }^{7}$

The analysis in the time domain was performed by means of SDNN (standard deviation of normal-tonormal R-R intervals; overall variability of heart rate) and RMSSD (root-mean square of differences between adjacent normal $\mathrm{R}-\mathrm{R}$ intervals in a time interval, parasympathetic modulation). ${ }^{7}$

\section{Nonlinear methods}

The nonlinear indices evaluated were derived from the recurrence plot. The following indices were obtained: recurrence rate (REC), determinism (DET), and Shannon entropy (ES), as well as the qualitative analysis of the recurrence plot.

The recurrence plot is the visualisation of a square matrix in which the elements of the matrix correspond to the moments in which a state of a dynamic system repeats - columns and rows correspond to a particular couple of times. The recurrence plot reveals 
the moments when the trajectory in the phase space of the dynamical system returns approximately to the same area in the phase space, ${ }^{26}$ and it may be quantitatively and qualitatively analysed.

Qualitative analysis was carried out by visualisation of the vertical, horizontal, and diagonal lines of the recurrence plot. The diagonal lines reflect the repeating sequence of states in the system, and the horizontal and vertical lines result from a persistent state during a time interval. ${ }^{26}$ In healthy individuals, the recurrence plot has a diagonal square and is less apparent, indicating higher heart rate variability, whereas in subjects with cardiac abnormalities the recurrence plot presents more apparent squares, indicating the inherent frequency and low heart rate variability related to an autonomic nervous system recurrence. Furthermore, if the recurrence plot is randomness it will show no structure and an uniform distribution, and there will be no pattern identifiable in the plot. Thus this plot is related to a autonomic nervous system with randomness trend. ${ }^{19}$

Quantitative analysis of the recurrence plot enables the extraction of three indices: REC, DET, and ES. The REC is the ratio of all recurrent states (return points) for all possible states, and therefore the probability of recurrence of a particular state; it takes into account the ratio of ones and zeros in the matrix of the recurrence plot, measuring their return points. The DET is the number of points present in the recurrent formation of the diagonal lines over all the points of relapse and it is related to the degree of predictability of the system. ${ }^{19}$

The ES is a measure that describes the irregularity, complexity, or uncertainty of an experimental time series, representing the energy expended to produce work. ${ }^{19}$ Mathematically, the calculation of ES signal is negative - the higher the entropy value the more information and greater adaptability to the environment. ${ }^{27}$ Thus, if ES is large, then the distribution is flat - all the random patterns are distributed and the series takes as much information as possible. On the other hand, if small, there is likely a subset of patterns. ${ }^{28}$

\section{Mathematics series}

Mathematical and linear random series were created ${ }^{29}$ in order to compare the patterns of behaviour of these series with those obtained by the series of the volunteers in this study. The series obtained were also analysed using the visual recurrence analysis software to obtain the indices derived from the recurrence plot.

The random series were constructed in Excel using the formula Random ()$\times 100$, random values between 0 and 100 were obtained after excluding the decimal places. The linear series was obtained through a series constructed with prime numbers between 2 and $3800 .{ }^{29}$

\section{Statistical analysis}

Standard statistical methods were used for the calculation of means, standard deviations, maximum and minimum values, and confidence intervals of 95\%. Normal Gaussian distribution of the data was verified by the Shapiro-Wilk goodness-of-fit test (z value $>1.0$ ). For parametric distribution, we applied the Student t-test, and for non-parametric distribution we applied the Mann-Whitney test. Differences were considered significant when the probability of a Type I error was lower than 5\% $(\mathrm{p}<0.05)$. The calculation of the study power with the number of subjects analysed and significance level of $5 \%$ (two-tailed test) confirmed a power higher than $80 \%$ to detect differences between the variables.

\section{Results}

Table 1 shows the characteristics of both the groups. There were no significant differences between the groups.

All the volunteers from the type 1 diabetes mellitus group were insulin dependent. In addition, three subjects $(15 \%)$ used medication to control blood pressure, three (15\%) for thyroid disorders, two (10\%) for peripheral neuropathy symptoms, and two $(10 \%)$ used contraceptives. Regarding co-morbidities, the control group included two volunteers classified as obesity grade 1 , and one subject in the type 1 diabetes mellitus group was classified as obesity grade $3 .^{21}$

Table 2 presents the values of the DET, REC, and ES indices derived from recurrence plot quantitative analysis. Smaller values of these indices were observed for the type 1 diabetes mellitus group compared with the control group $(\mathrm{p}<0.05)$.

Table 2. Mean values, followed by their respective standard deviations of DET, REC, and ES indices derived by RP for the studied groups.

\begin{tabular}{lccc}
\hline & DM1 & Control & p value \\
\hline DET (\%) & $96.14 \pm 1.56[95.41-96.88]$ & $97.13 \pm 0.92[96.73-97.53]$ & 0.0145 \\
REC (\%) & $19.65 \pm 5.44[17.10-22.20]$ & $23.56 \pm 4.68[21.53-25.58]$ & 0.0153 \\
ES (bits) & $4.06 \pm 0.32[3.92-4.20]$ & $4.31 \pm 0.29[4.18-4.44]$ & 0.0057 \\
\hline
\end{tabular}

$\mathrm{DET}=$ determinism; $\mathrm{DM} 1=$ diabetes mellitus type $1 ; \mathrm{ES}=$ Shannon entropy $\mathrm{REC}=$ recurrence rate; $\mathrm{RP}=$ recurrence plot

Mean \pm standard deviation $[95 \% \mathrm{CI}]$ 
Regarding the qualitative analysis of recurrence plot, representative samples of the groups are presented in Figure 1. The selected recurrence plot of the individuals presented the DET and REC values closer to the average for their respective groups.

The recurrence plot of the healthy subjects presented a pattern with more square and vertical and horizontal lines apparent in comparison with the diabetic recurrence plot, which showed the least square lines. Furthermore, the intra-group analysis showed that the control group recurrence plot patterns were between individuals, which did not occur in the diabetic subjects' recurrence plot, which showed greater variation.

Table 3 shows the results of the mathematical models used to compare behaviour of the time random and linear series with the average values of the groups studied. It is worth noting that the average value of the type 1 diabetes mellitus group is tending towards randomness when compared with the average value of the control group.

Table 4 displays values of the heart rate variability indices obtained in the time and frequency domains. We observed significantly increased values of $\mathrm{LF}\left(\mathrm{ms}^{2}\right)$, $\mathrm{HF}\left(\mathrm{ms}^{2}\right)$, RMSSD, and SDNN in the control group.

\section{Discussion}

This study was carried out to evaluate nonlinear dynamics of heart rate in young type 1 diabetic subjects

(a)

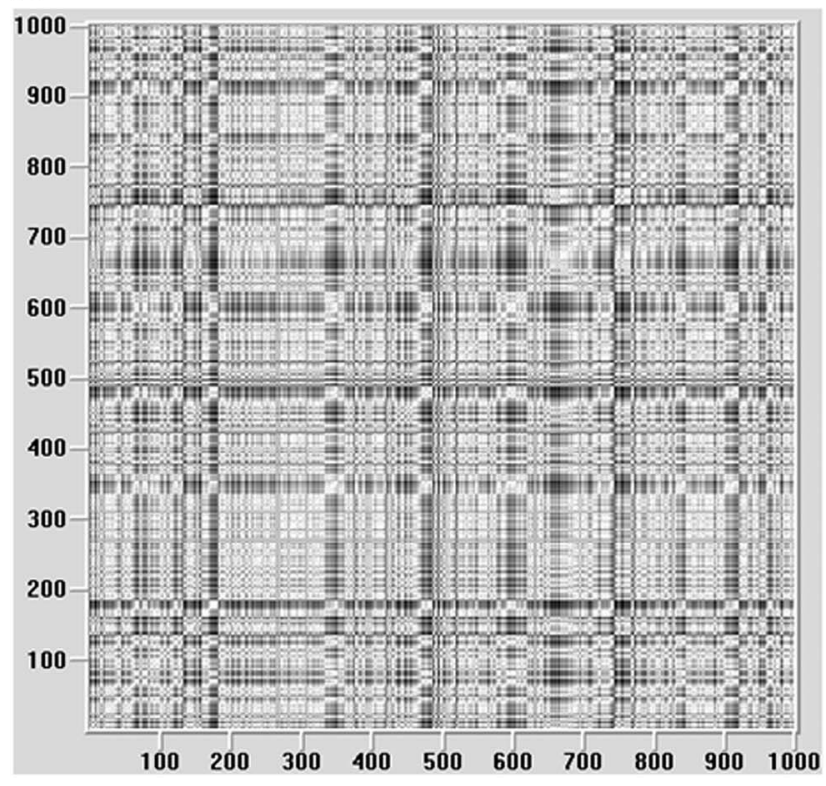

through analysis of recurrence plots. Our results indicate that young diabetic subjects demonstrate reduced DET, REC, and ES indices compared with healthy young control subjects, suggesting that this group has a tendency to random cardiac autonomic regulation behaviour. In other words, they present impaired cardiac autonomic regulation. ${ }^{30}$ Recurrence plot qualitative analysis showed that diabetic patients had a pattern with less squares and apparent vertical and horizontal lines, as well as greater figures of variation between individuals compared with the recurrence plot of controls.

These findings were accompanied by reduced sympathetic and parasympathetic regulation of the heart in the type 1 diabetes mellitus group, observed by heart rate variability linear indices analysis.

Using the REC, DET, and ES values obtained from random linear mathematical series to compare the

Table 3. Values of REC, DET, and ES of the studied groups and the mathematical models of time series: random, diabetic group, control group, and linear.

\begin{tabular}{lrrr}
\hline & REC & DET & ES \\
\hline Random & 6.20 & 87.10 & 2.88 \\
Diabetics & 19.65 & 96.14 & 4.06 \\
Control & 23.56 & 97.13 & 4.31 \\
Linear & 41.40 & 99.90 & 7.31 \\
\hline
\end{tabular}

$\mathrm{DET}=$ determinism; $\mathrm{ES}=$ Shannon entropy; $\mathrm{REC}=$ recurrence rate

(b)

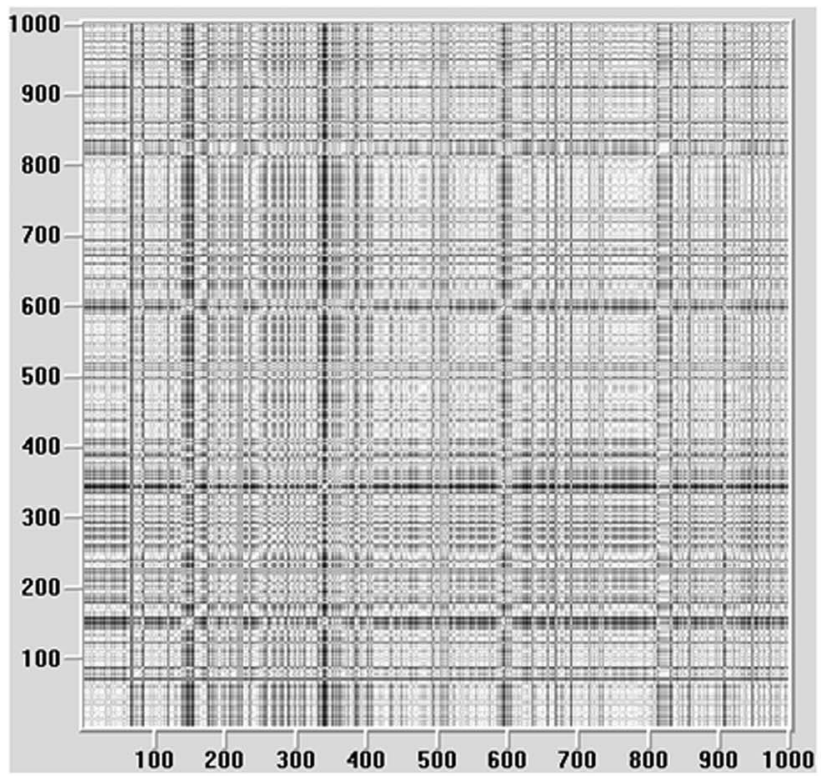

Figure 1.

(a) Recurrence plot of young healthy controls (REC: 26.35 and DET: 97.64), (b) recurrence plot of young diabetic individuals (REC: 17.69 and DET: 96.14). It is noticed that figure $A$ has more squares and lines along the whole image, compared with figure B, and this pattern is present in all the images of the control group; however, no image pattern is present in the type 1 diabetes mellitus group, in which the number of lines and squares formed are different between the diabetes subjects. 
Table 4. Mean values, followed by the respective standard deviations of HRV indices obtained in the time and frequency domains of the studied groups.

\begin{tabular}{lccr}
\hline & DM1 & Control & p value \\
\hline RMSSD (ms) & $35.36 \pm 17.63[37.11-43.62]$ & $51.14 \pm 22.20[41.54-60.75]$ & 0.0145 \\
SDNN (ms) & $40.41 \pm 16.25[32.80-48.01]$ & $66.39 \pm 24.06[55.98-76.80]$ & 0.0002 \\
LF $\left(\mathrm{ms}^{2}\right)$ & $608.50 \pm 577.05[338.43-878.57]$ & $1.196 .50 \pm 819.34[842.19-1550.9]$ & 0.0039 \\
HF $\left(\mathrm{ms}^{2}\right)$ & $599.20 \pm 530.85[350.76-847.64]$ & $1.115 .80 \pm 870.01[739.54-1492.0]$ & 0.0228 \\
LF (un) & $52.06 \pm 13.94[45.53-58.59]$ & $53.93 \pm 13.77[47.98-59.89]$ & 0.6605 \\
HF (un) & $47.93 \pm 13.94[41.40-54.46]$ & $46.06 \pm 13.77[40.10-52.01]$ & 0.6605 \\
LF/HF & $1.34 \pm 1.01[0.87-1.82]$ & $1.43 \pm 1.04[0.97-1.88]$ & 0.3874 \\
\hline
\end{tabular}

$\mathrm{DM} 1=$ diabetes mellitus type $1 ; \mathrm{HF}=$ high frequency; HRV = heart rate variability; $\mathrm{LF}=$ low frequency; LF/HF = low and high frequency ratio; $\mathrm{RMSSD}=$ root mean square of the sum of squares of differences between $\mathrm{iRR}$ adjacent; SDNN $=$ standard deviation of all normal $\mathrm{R}-\mathrm{R}$ intervals recorded in a time interval

Mean \pm standard deviation $[95 \% \mathrm{CI}]$

values found in all groups, we observed that the type 1 diabetes mellitus group had values close to random series, suggesting that type 1 diabetes mellitus subjects have a standard tendency towards randomness, which may explain the lower values of the DET and REC indices reported in our study.

The presence of randomness produces unpredictable cardiac autonomic modulation behaviour, ${ }^{31}$ and this random behaviour can influence, directly or indirectly, the occurrence of complications of type 1 diabetes mellitus. ${ }^{32}$

Unlike the results presented in our investigation, a previous study evaluated heart rate variability in healthy young subjects and type 1 diabetes mellitus patients. The authors described higher values of DET for individuals with type 1 diabetes mellitus, indicating a reduced complexity in the control of heart rate in the group with diabetic patients; ${ }^{17}$ however, the methodology used in the mentioned study included restriction of ANS stimulants for 12 hours before evaluation, the heart rate variability analysis was performed in the morning, and the authors did not exclude smokers. These criteria are different from that of our study, which may have influenced the results and contributed to the differences in results.

Regarding ES, we observed higher values for healthy subjects compared with diabetic individuals. The ES reduction is related to sympathetic-vagal imbalance, which can predict depressed global modulation of heart rate as well as pathological conditions such as malignant cardiac arrhythmias, heart attack, and even sudden death, ${ }^{28}$ indicating that patients with type 1 diabetes are more prone to such conditions.

For the recurrence plot qualitative analysis of the type 1 diabetes mellitus group, we reported a pattern graph with lower recurrence, which was against the lowest values for DET and REC indices observed in the qualitative analysis of this group. Volunteers in this group also showed a pattern of more diverse recurrence plot figures, indicating autonomic regulation of the heart with greater variation.

The index that evaluates global modulation of heart rate, the SDNN index, ${ }^{7}$ was reduced in the type 1 diabetes mellitus group, suggesting that these individuals have reduced overall regulation of the heart, which is an indicator of abnormal function and insufficient adaptation of the cardiac autonomic regulation. ${ }^{7,33}$ This finding may indicate a high predictor of mortality, possibly due to heart attack, atrium fibrillation, other cardiac arrhythmias, congestive heart failure, and ischaemic heart disease. ${ }^{4,5,33}$

In agreement with this result, a study with 17 type 1 diabetes mellitus patients, aged between 12 and 30 years, reported decreased SDNN index in these individuals. ${ }^{13}$ In contrast, Trunkvalterova et $\mathrm{al}^{15}$ analysed the SDNN index in 14 type 1 diabetes mellitus patients (mean age $22.3 \pm 1.2$ years old) and found no significant differences between the control and the type 1 diabetes mellitus group. The authors explain that the lack of differences may be related to the small sample size used.

Our findings also indicate that the indices that determine the parasympathetic (RMSSD and $\mathrm{HF} \mathrm{ms}^{2}$ ) and the sympathetic (LF ms ${ }^{2}$ ) modulation of the heart were lower in the type 1 diabetes mellitus group compared with the control group. This condition can produce responses in subjects' physiology that are not efficient to induce alarm reactions and considered as an increased risk of cardiovascular diseases and significantly increased mortality rate. ${ }^{34,35}$ Similar results for the LF and HF indices in children with type 1 diabetes melllitus aged between 8 and 12 years were also reported in the literature. ${ }^{10}$

Our study presents some points that are noteworthy. The different time of diagnosis among the type 1 diabetes mellitus subjects and the presence of obesity in both groups are limitations that should be mentioned. Regarding obesity, although the type 1 
diabetes mellitus group presented two volunteers classified as obesity grade 1 and 3, previous research pointed out that this situation does not affect the autonomic nervous system function. ${ }^{36}$

In this context, it has been observed that the presence of type 1 diabetes mellitus causes major changes in the cardiac autonomic modulation, and these changes are already present in the young population, which has no other typical complications triggered by the type 1 diabetes mellitus. Change in the heart rate variability dynamics is an important factor to be prevented and treated, as its occurrence is associated with a worse prognosis and quality of life, ${ }^{4}$ and it may influence the occurrence of various diseases such as severe arrhythmias, dysfunction of the vascular atherosclerosis, stroke, and even sudden death. ${ }^{37,38}$

Thus, it is understood that early identification of cardiac autonomic changes is important, as the treatment strategies can be prepared in a more direct manner, and therefore prevent the onset or prevent complications that this disease induces, creating a better prognosis for type 1 diabetes mellitus.

\section{Acknowledgements}

The authors are grateful to CNPq's (National Council of Scientific and Technological Development) financial support for this study (Protocol no. 477442/2012-9).

\section{Financial Support}

We received financial support from $\mathrm{CNPq}$ (National Council of Scientific and Technological Development).

\section{Conflicts of Interest}

The authors declare that there are no conflicts of interest.

\section{Ethical Standards}

The authors declare that all study procedures were approved by the Ethics Committee in Research of our Institution (Proc: 47/2011) and followed the rules established by the 466/2012 Resolution of The National Health Council.

\section{References}

1. Iser BPM, Stopa SR, Chueiri PS, et al. Self-reported diabetes prevalence in Brazil: results from National Health Survey 2013. Epidemiol Serv Saude 2015; 24: 305-314.

2. Traon AP, Fontaine S, Tap G, Guidolin B, Senard Jl, Hanaire H. Cardiovascular autonomic neuropathy and other complications in type 1 diabetes. Clin Auton Res 2010; 20: 153-160.

3. Pop-Busui R, Evans GW, Gerstein HC, et al. Effects of cardiac autonomic dysfunction on mortality risk in the action to control cardiovascular risk in diabetes (ACCORD) trial. Diabetes Care 2010; 33: 1578-1584.
4. Rolim L, Sá R, Chacra A, Dib S. Neuropatia autonômica cardiovascular diabética: fatores de risco, impacto clínico e diagnóstico precoce. Arq Bras Cardio 2008; 90: 24-32.

5. Villegas JER, Espinosa EL, Moreno DFR, Echeverry PCC, Rodrigues WA. Heart rate variability dynamics for the prognosis of cardiovascular risk. PLos One 2011; 6: 1-15.

6. Vanderlei LCM, Silva RA, Pastre CM, Azevedo FM, Godoy MF Comparison of the Polar S810i monitor and the ECG for the analysis of heart rate variability in the time and frequency domains. Braz J Med Biol Res 2008; 41: 854-859.

7. Vanderlei LCM, Pastre CM, Hoshi RA, Carvalho TD, Godoy MF. Noções básicas de variabilidade da frequência cardíaca e sua aplicabilidade clínica. Rev Bras Cir Cardiovasc 2009; 24: 205-217.

8. Vanderlei FM, Rossi RC, Souza NM, et al. Heart rate variability in healthy adolescents at rest. J Hum Growth Dev 2012; 22: 173-178.

9. Ferreira L, Souza N, Bernardo A, Vitor A, Valenti V, Vanderlei L. Variabilidade da frequência cardíaca como recurso em fisioterapia: análise de periódicos nacionais. Fisioter Mov 2013; 26: 25-36.

10. Chen S-R, Lee Y-J, Chiu H-W, Jeng C. Impact of physical activity on heart rate variability in children with type 1 diabetes. Childs Nerv Sys 2008; 24: 741-747.

11. Seyd A, Joseph P, Jacob J. Automated diagnosis of diabetes using heart rate variability signals. J Med Syst 2012; 36: 1935-1941.

12. Lucini D, Zuccotti G, Malacarne M, et al. Early progression of the autonomic dysfunction observed in pediatric type 1 diabetes mellitus. Hypertension 2009; 54: 987-994.

13. Javorka M, Trunkvalterova Z, Tonhajzerova I, Javorkova J, Javorka K, Baumert M. Short-term heart rate complexity is reduced in patients with type 1 diabetes mellitus. Clin Neurophysiol 2008; 119: 1071-1081.

14. Hägglund H, Uusitalo A, Peltonen JE, et al. Cardiovascular autonomic nervous system function and aerobic capacity in type 1 diabetes. Front Physiol 2012; 3: 356.

15. Trunkvalterova Z, Javorka M, Tonhajzerova I, et al. Reduced shortterm complexity of heart rate and blood pressure dynamics in patients with diabetes mellitus type 1: multiscale entropy analysis. Physiol Meas 2008; 29: 817.

16. Vitor A, Souza N, Lorenconi R, et al. Nonlinear methods of heart rate variability analysis in diabetes. HealthMed 2012; 6: $2647-2653$.

17. Javorka M, Trunkvalterova Z, Tonhajzerova I, Lazarova Z, Javorkova J, Javorka K. Recurrences in heart rate dynamics are changed in patients with diabetes mellitus. Clin Physiol Funct Imaging 2008; 28: 326-331.

18. Marwan N, Kurths J. Nonlinear analysis of bivariate data with cross recurrence plots. Phys Lett A 2002; 302: 299-307.

19. Ferreira MT, Messias M, Vanderlei LCM, Pastre CM. Análise comparativa de sáries temporais da variabilidade da frequência cardíaca de indivíduos saudáveis com indivíduos que apresentam insuficiência renal crônica. Tend Mat Apl Comput 2010; 11: $141-150$.

20. Hallal P, Gomez L, Parra D, et al. Lições aprendidas depois de 10 anos de uso do IPAQ no Brasil e Colômbia. J Phys Act Health 2010; 7: S259-S264.

21. Abeso. Diretrizes brasileiras de obesidade - Associação brasileira para o estudo da obesidade e da síndrome metabólica 2009, 1-83.

22. Ferreira MG, Valente JG, Gonçalves-Silva RMV, Sichieri R. Accuracy of waist circumference and waist-to-hip ratio as predictors of dyslipidemia in a cross-sectional study among blood donors in Cuiabá, Mato Grosso State, Brazil. Cad Saúde Pública 2006; 22: 307-314.

23. Sociedade Brasileira de Cardiologia. VI Diretrizes brasileiras de hipertensão. Arq Bras Cardiol 2010; 95: 1-51.

24. Gamelin FX, Berthoin S, Bosquet L. Validity of the polar S810 heart rate monitor to measure R-R intervals at rest. J Exerc Sci Fit 2006; 38: 5887-5893. 
25. Godoy MF, Takakura IT, Correa PR. Relevância da análise do comportamento dinâmico nãolinear (Teoria do Caos) como elemento prognóstico de morbidade e mortalidade em pacientes submetidos à cirurgia de revascularização miocárdica. Arq Ciênc Saúde 2005; 12: 167-171.

26. Souza E. Caracterização de sistemas dinâmicos através de gráficos de recorrência. Curitiba: Universidade Federal do Paraná. Dissertação 2008; 1-97.

27. Selig FA, Tonolli ER, Silva EVCM, Godoy MF. Variabilidade da frequência cardíaca em neonatos prematuros e de termo. Arq Bras Cardiol 2011; 96: 443-449.

28. Kunz VC, Souza RB, Takahashi ACM, Catai AM, Silva E. The relationship between cardiac autonomic function and clinical and angiographic characteristics in patients with coronary artery disease. Braz J Phys Ther 2011; 15: 503-510.

29. Baptista MA. Gráficos de recorrência e de poincaré na análise da quantidade de internações por diferentes grupos nosológicos, ocorridas ao longo de uma década, em um hospital de ensino [Tese para título de Doutor]. São José do Rio Preto: Faculdade de Medicina Curso de Pós-graduação em Ciências da Saúde 2011.

30. Peng CK, Havlin S, Hausdorff JM, Mietus JE, Stanley HE, Goldberger AL. Fractal mechanisms and heart rate dynamics: long-range correlations and their breakdown with disease. J Electrocardiol 1995; 28: 59-65.

31. Higgins J. Nonlinear systems in medicine. Yale J Biol Med 2002; 75: $247-260$.
32. Hotta N, Otsuka K, Murakami S, et al. Fractal analysis of heart rate variability and mortality in elderly community-dwelling people: Longitudinal investigation for the longevity and aging in Hokkaido county (LILAC) study. Biomed Pharmacother 2005; 59: S45-S48.

33. Mogensen UM, Jensen T, Kober L, et al. Cardiovascular autonomic neuropathy and subclinical cardiovascular disease in normoalbuminuric type 1 diabetic patients. Diabetes 2002; 61: $1822-1830$

34. Xhyheri B, Manfrini O, Mazzolini M, Pizzi C, Bugiardini R. Heart rate variability today. Prog Cardiovasc Dis 2012; 55: 321-31.

35. Rodrigues TC, Ehrlich J, Hunter CM, Kinney GL, Rewers M, Snell-Bergeon JK. Reduced heart rate variability predicts progression of coronary artery calcification in adults with type 1 diabetes and controls without diabetes. Diabetes Technol Ther 2010; 12: 963-969.

36. Maser RE, Lenhard MJ. Obesity is not a confounding factor for performing autonomic function tests in individuals with diabetes mellitus. Diabetes Obes Metab 2002; 4: 113-117.

37. Soydan N, Bretzel RG, Fischer B, Wagenlehner F, Pilatz A, Linn $T$. Reduced capacity of heart rate regulation in response to mild hypoglycemia induced by glibenclamide and physical exercise in type 2 diabetes. Metabolism 2013; 62: 717-724.

38. Matei D, Popescu CD, Ignat B, Matei R. Autonomic dysfunction in type 2 diabetes mellitus with and without vascular dementia. J Neurol Sci 2013; 325: 6-9. 